\title{
The Emergency Framing of Solar Geoengineering: Time for a Different Approach
}

\section{Citation}

Horton, Joshua B. 2015. "The Emergency Framing of Solar Geoengineering: Time for a Different Approach." The Anthropocene Review 2(2): 147-151.

\section{Published Version}

doi:10.1177/2053019615579922

\section{Permanent link}

http://nrs.harvard.edu/urn-3:HUL.InstRepos:23017250

\section{Terms of Use}

This article was downloaded from Harvard University's DASH repository, and is made available under the terms and conditions applicable to Other Posted Material, as set forth at http:// nrs.harvard.edu/urn-3:HUL.InstRepos:dash.current.terms-of-use\#LAA

\section{Share Your Story}

The Harvard community has made this article openly available.

Please share how this access benefits you. Submit a story.

Accessibility 


\section{The Emergency Framing of Solar Geoengineering: Time for a Different Approach}

Over the past several years, solar geoengineering, also known as solar radiation management (SRM), has been presented to the public as a possible last-ditch response option in the event of a "climate emergency" (Blackstock et al., 2009; Long et al., 2011). Many technical and scientific uncertainties remain, but the available evidence suggests that methods such as stratospheric aerosol injection (SAI), which theoretically would reflect a small but significant amount of incoming shortwave radiation sufficient to restore global mean temperatures to approximately preindustrial values, would act relatively quickly, possibly within months (Royal Society, 2009). The fast-acting nature of such measures would seem to make them especially suitable for urgent situations requiring quick action. In the climate context, such scenarios are commonly referred to as "climate emergencies."

Within the geoengineering research community itself, however, framing SRM in terms of a climate emergency has drawn increasing criticism from both opponents and advocates of more research. This criticism has been fragmented and disparate, originating from natural scientists, social scientists, philosophers, and others. Yet while skepticism toward emergency framing has become increasingly uniform within the research community-even across otherwise contrasting disciplinary orientations and normative outlooks-viewing SRM through the lens of climate emergencies remains a primary mode of talking about geoengineering in both mainstream media and popular science accounts of this emerging field. In this brief article, I will bring together and consider the key objections to the emergency framing of solar geoengineering, and argue that this framing should be dropped from future public policy debates on managing climate risks.

\section{Defining Climate Emergencies}

In assessing the soundness and utility of the emergency framing, the starting point is an examination of the concept of "climate emergency." Put simply, climate scientists have no agreed definition of what would constitute a climate emergency, and are nowhere close to reaching consensus on the issue. When discussing "emergencies," scientists and other researchers tend to have one of two physical phenomena in mind. The first of these is the so-called runaway greenhouse scenario, in which an atmosphere supersaturated with greenhouse gases (GHGs) restricts the emission of longwave radiation to space, triggering positive feedbacks, boiling the oceans, and transforming the Earth into a planet more like Venus. All available evidence indicates that such a scenario is squarely implausible (Goldblatt and Watson, 2012).

The second, more plausible "emergency" scenario entails crossing a climate tipping point and thereby pushing a planetary subsystem into a qualitatively different state (Lenton et al., 2008). A number of possible tipping points have been identified, and 
indeed paleoclimatic data show multiple instances of abrupt, nonlinear changes in the climate system, for example, Dansgaard-Oeschger events (sudden, short-lived temperature increases) and Heinrich events (extreme, rapid declines in temperature). However, the Intergovernmental Panel on Climate Change (IPCC) in its Fifth Assessment Report (AR5) judged that few if any currently known potential tipping points are simultaneously abrupt, irreversible, and likely to be crossed this century (IPCC Working Group II, 2013). Another recent study put the related concept of "planetary" tipping points in serious doubt (Brook et al., 2013). Even those researchers most closely associated with theorizing about tipping points stress the limitations of their models and the multitude of questions remaining to be answered (Lenton, 2013). In sum, scientific research into tipping points remains at an early stage, and existing evidence provides a decidedly weak foundation from which to argue that an emergency SRM intervention might be required.

Whether envisioned in terms of a runaway greenhouse effect or, more credibly, climate tipping points, what is clear is that the concept of "climate emergency" is socially constructed. In other words, an emergency (climate or otherwise) is ultimately a shared idea, rather than objective reality. The climate system is of course replete with acute, high-risk events, but whether a given event is regarded as an "emergency" depends entirely on how society defines "emergency." Moreover, a large number of social phenomena, ranging from crop failures and infrastructure collapse to "climate refugee" crises and "climate wars," might be blamed on climate change and labeled as "emergencies" even in the absence of causal evidence. The attribution of physical effects to climate change is already highly contested, and conclusively attributing social outcomes to climate is even more controversial if not impossible. Either case begs the question, who would be empowered to define a climate emergency and determine whether a particular event qualifies as such?

The obvious candidates, as suggested by the above, are climate scientists or other qualified experts. And yet the apparent necessity of ceding some degree of decisionmaking authority over an issue as critical as planetary emergencies to a select group of specialized experts has led to criticism that emergency framing promotes technocracy (Heyward and Rayner, 2013). On this view, government by experts has the potential to erode democratic practices, and public policy framings that favor rule by technical experts over popular representatives should, at a minimum, be challenged.

\section{Society and the "State of Exception"}

A more systematic political objection to the emergency framing of solar geoengineering relates to the risks entailed in any declaration of emergency. Commentators have long noted that when public authorities declare emergencies, power is inevitably concentrated in the hands of a relative few, enhancing opportunities for abuse, at times on a grand scale. The transformation of ancient Rome from a Republic into an Empire stands as a paradigmatic case of this phenomenon. For centuries, the Republic's ordinary political institutions were 
periodically supplemented by the formal appointment of a dictator, who was granted near-absolute power to repel extraordinary foreign and domestic threats. Despite a system of safeguards intended to minimize the risk of abuse, the supremely powerful dictatorship eventually overwhelmed its institutional rivals in a process that culminated in the establishment of the Empire under Julius Caesar.

The authoritarian tendency inherent in states of emergency has been a point of contention among political theorists, particularly over the past century.

Controversial German philosopher Carl Schmitt embraced the potential for decisive state action made possible by a "state of exception" (Schmitt, 2014). But most liberal theorists, such as Italian philosopher Giorgio Agamben, have criticized emergency modes of government as fundamentally undemocratic (Agamben, 2005). During the Indian Emergency of 1975-77, for instance, the purported need to quell "internal disturbance" was used to justify widespread derogations of civil and political rights. Other episodes such as the emergency decrees issued under the Weimar Republic, Egypt's longstanding Emergency Law, and emergency rule under Augusto Pinochet in Chile substantiate concerns about the autocratic propensity of emergency proclamations. Indeed, for some observers, we now live in "a world of emergencies" requiring constant vigilance in the face of endless invocations of emergency, crisis, and catastrophe (Calhoun, 2004).

Many members of the incipient geoengineering research community have criticized the emergency framing of SRM for the socially corrosive ethical and political effects associated with the proclamation of emergency powers (Hulme, 2014). Similarly, researchers have also criticized this framing as based on underdeveloped scientific concepts and insufficient empirical evidence (Keith, 2013). However, as already noted, the climate system does periodically experience abrupt, nonlinear events, and at the same time, solar geoengineering methods such as SAI (if proven to work) appear to be the only climate policy tools available that could act effectively to address such risks on short notice. The question, then, is whether SRM should have any role to play in acute, high-risk situations that might be labeled "climate emergencies."

\section{Conditions for Emergency Deployment}

To answer this question, it is vital to specify exactly what is meant by "emergency." The concept of emergency is arguably composed of three key attributes:

1. High risk, or the possibility of significant loss - The stakes must be high, with a reasonable likelihood of occurrence and damages of potentially substantial magnitude.

2. A sense of urgency or immediacy-Circumstances must call for a rapid response.

3. A feeling of necessity-The response in question must be viewed as essential to avoiding loss.

Each of these attributes has an inescapably subjective element: what is "significant" is in the eye of the beholder, while "senses" and "feelings" depend entirely on 
individual points of view. To repeat from above, the idea of emergency is ultimately a social construct. In the climate policy context, social construction and therefore subjective judgments about what constitutes an emergency encompass both the climatic phenomenon in question and possible responses to it.

As has been discussed, the most compelling scientific case for a phenomenon that might be regarded as a climate emergency is found in the literature on tipping points. Commentators have suggested many possible climate tipping points, but only about ten critical regional thresholds are regarded as plausible by the scientific community; these include collapse of the Atlantic Meridional Overturning Circulation, collapse of the Greenland or West Antarctic ice sheets, permafrost carbon release, clathrate methane release, tropical forest dieback, boreal forest dieback, disappearance of summer Arctic sea ice, long-term droughts, and disruptions to monsoonal circulations (IPCC Working Group II, 2013). Among these potential tipping points, none is considered to be likely, highly damaging, and abrupt (IPCC Working Group II, 2013). (The closest candidate is Arctic summer sea ice loss, but associated damages are seen as manageable.)

The climate system is, of course, unpredictable, and critical elements remain poorly understood. The possibility of a dangerous, previously unidentified tipping point or other climatic phenomenon cannot be ruled out completely, in which case solar geoengineering might still be an appropriate response strategy. Even in this situation, however, a number of additional questions must be answered satisfactorily in order to treat SRM as a viable emergency response option. Most importantly, and most obviously, is SRM feasible in terms of its efficacy and risks? Researchers have raised serious doubts regarding the very possibility of testing SRM short of full-scale deployment. However, micro- and meso-scale field trials involving process, scaling, and climate response experiments should be capable of providing answers to many key questions about the intended and unintended impacts of solar geoengineering (MacMynowski et al., 2011).

Beyond this, and assuming SRM is shown to be viable, is SRM the only feasible tipping point response option and hence necessary to avoid significant loss, or are other options such as robust adaptation available? Has a critical tipping point threshold already been crossed? If so, is the ensuing change reversible? If not, are early warning signs of approaching tipping points available? Can they be detected? Only if convincing answers were provided to all these questions would it be appropriate for policymakers to consider solar geoengineering as a serious climate emergency response option. In practice, of course, answers to these questions will likely be difficult to provide, frustratingly imprecise, and strongly contested.

Even if these hurdles were overcome, the acute sociopolitical risks associated with declarations of emergency would remain, and might well argue against emergency action despite the real dangers involved. These risks are not insurmountable, as a variety of institutional solutions are available to restrain concentrations of power, mitigate the risk of abuse, and strengthen the liberal democratic underpinnings of 
otherwise unavoidable emergency government (Ferejohn and Pasquino, 2004). As a standard frame through which to consider the possible application of solar geoengineering techniques, however, a broad array of scientific and societal concerns counsels strongly against viewing SRM as a possible response to a climate emergency.

\section{Better Approaches}

Other forms of deployment offer better rationales for the possible use of SRM in the future. The most common alternative, known as "peak shaving," would entail application of SAI or some other type of solar geoengineering to reduce the worst effects of peak GHG emissions while implementing an ambitious program of mitigation and adaptation. One variant of peak shaving would involve a gradual ramp-up of solar geoengineering until a modest plateau is reached; as emissions declined, so too would injections of stratospheric aerosols (Keith, 2013). Another potential approach would utilize SRM on a regional scale, for example in the Arctic, in order to address specific, localized damages from climate change.

These and other deployment scenarios contemplate taking advantage of SRM's unique combination of high-leverage, fast-acting, and low-cost (at least in direct terms) characteristics within well-defined limits, while avoiding reliance on unsubstantiated science, appeals to political expediency, and the slippery slope of emergency rule. As Mike Hulme writes, "Climate emergencies are made, not discovered, and what matters most is who announces them and for what purpose" (Hulme, 2014: 134-135). Based on current understanding, framing solar geoengineering as a possible a response to climate emergencies is both unwarranted and unwise. The time has come for the geoengineering research community and other interested parties to abandon this approach.

\section{References}

Agamben G (2005) State of Exception. Chicago: University of Chicago Press.

Blackstock JJ, Battisti DS, Caldeira K et al. (2009) Climate Engineering Responses to Climate Emergencies. Santa Barbara, CA: Novim.

Brook BW, Ellis EC, Perring MP et al. (2013) Does the Terrestrial Biosphere Have Planetary Tipping Points? Trends in Ecology \& Evolution 28(7): 396-401.

Calhoun C (2004) A World of Emergencies: Fear, Intervention, and the Limits of Cosmopolitan Order. Canadian Review of Sociology/Revue canadienne de sociologie 41(4): 373-395.

Ferejohn J and Pasquino P (2004) The Law of the Exception: A Typology of Emergency Powers. International Journal of Constitutional Law 2(2): 210-239. 
Goldblatt C and Watson AJ (2012) The Runaway Greenhouse: Implications for Future Climate Change, Geoengineering and Planetary Atmospheres. Philosophical Transactions of the Royal Society A 370(1974): 4197-4216.

Heyward C and Rayner S (2013) Apocalypse Nicked! Climate Geoengineering Governance Working Paper Series. Oxford, UK: ESRC.

Hulme M (2014) Can Science Fix Climate Change? Cambridge, UK: Polity Press.

Intergovernmental Panel on Climate Change Working Group II (2013) Climate Change 2013: The Physical Science Basis. Cambridge, UK: Cambridge University Press.

Keith D (2013) A Case for Climate Engineering. Cambridge, MA: MIT Press.

Lenton TM (2013) Can Emergency Geoengineering Really Prevent Tipping Points? Geoengineering Our Climate Working Paper and Opinion Article Series. Available at: http://geoengineeringourclimate.com/2013/06/25/can-emergencygeoengineering-really-prevent-climate-tipping-points-opinion-article/.

Lenton TM, Held H, Kriegler E et al. (2008) Tipping Elements in the Earth's Climate System. Proceedings of the National Academy of Sciences 105(6): 1786-1793.

Long J, Rademaker S, Anderson JG et al. (2011) Geoengineering: A National Strategic Plan for Research on the Potential Effectiveness, Feasibility, and Consequences of Climate Remediation Technologies. Washington, DC: Bipartisan Policy Center.

MacMynowski DG, Keith DW, Caldeira K et al. (2011) Can We Test Geoengineering? Energy \& Environmental Science 4: 5044-5052.

Royal Society (2009) Geoengineering the Climate: Science, Governance and Uncertainty. London: Royal Society.

Schmitt C (2014) Dictatorship: From the Origin of the Modern Concept of Sovereignty to Proletarian Class Struggle. Cambridge, UK: Polity Press. 